\title{
Development of Teaching and Learning Materials for Geometry through Problem-based Learning Model
}

\author{
Wen Haw Chen ${ }^{\text {* }}$ \\ ${ }^{a}$ Department of Applied Mathematics, Tunghai University, Taichung, Taiwan \\ *Corresponding author: whchen@thu.edu.tw
}

\section{Article history}

Received :11 December 2012

Received in revised form

30 August 2013

Accepted :15 September 2013

\begin{abstract}
Problem-based learning (PBL) model can help students to study oneself from the question even more. This research hopes to think Luce Chapel in Tunghai University as the model to incorporate geometry in mathematics. The method comes to develop the teaching aid of the model of Luce chapel to excite students of different stages thinking deeply the designed questions and to assist teaching. We include the mathematics concepts incorporated in the teaching aid: The structure of 3 - dimensional space for elementary school students comes by way of designing and counting the building blocks; Lead the junior high school students to calculate the surface area, volume, and pile up the building blocks to utilize arithmetic progression; Let the high school student utilize elementary functions and conic sections. Moreover, by the fact that the chapel tiles levelly and smoothly, some advanced geometric concepts can be also introduced to university students.
\end{abstract}

Keywords: Problem-based learning model; geometry; teaching aid; Luce Chapel

(C) 2013 Penerbit UTM Press. All rights reserved.

\subsection{INTRODUCTION}

People acquire knowledge primarily through the experience of various sensations and actions. From the learning perspective, people learn through interactions with their environment and persistent knowledge is gradually learned from experience through the five senses and various actions. Therefore, teaching should combine social, scientific, and technological facts to assist students in establishing positive life values and conceptualizing their scientific concepts with learning activities that are designed to encourage them to discover and investigate nature, apply knowledge to various learning activities, and explain daily life problems. The ideal pedagogy is one that provides direct experience, namely object teaching. The conventional definition of object teaching is that teachers employ real objects to assist teaching delivery. These objects are effectively teaching aids that assist teachers in teaching and students. Several characteristics of teaching aids are detailed as follows:

(1) Facilitating interest in learning so that students become eager to learn.

(2) Inspiring students to think so that students have less difficult in understanding abstract concepts.

(3) Gaining experience and enhancing memory.

(4) Coping with individual differences and needs among students.
Recently, problem-based learning (PBL) method has been practiced broadly in the academic domain to facilitate self-learning when students are required to implement self-learning through questions. The core concepts of PBL are using professional knowledge, goal-setting, problem resolution, and evaluation of the results. PBL is applicable to various scenarios, although slight adjustments of the PBL process are necessary. Moreover, PBL has the following characteristics:

(1) Initiating learning with a real problem.

(2) Connection between the cognition and professional knowledge of the learners and the problems.

(3) Learning in small groups.

(4) A self-oriented learning model.

(5) Teachers or experts are considered helpers, not leaders.

The study uses Luce Chapel of Tunghai University as a teaching aid development target to extend various mathematical concepts by applying PBL, and develop related mathematical concept problems based on various student backgrounds in mathematical learning to integrate mathematical concepts into student learning environments in a more effortless manner. 


\subsection{PBL LITERATURE REVIEW}

PBL can be defined from various perspectives. Barrows and Tamblyn (1980) define PBL as the process in which learners learn knowledge by understanding or solving specific problems. Other studies (e.g., Fogarty, 1997) have considered PBL as a course model that focuses on real-world problems. Trop and Sage (2002) considered PBL as experiential learning because it can be employed as a curriculum organizer and a teaching strategy. Schmidt (1993) and Walton and Matthews (1989) indicated that PBL is a learning method and can be used to explain the process of learning and teaching. Numerous studies believed that PBL was initially developed as a teaching method for training medical students to discuss and solve clinical medical problems; and a student-centered and real problem solving apprenticeship-style contextualized teaching method or strategy that anchors learning and teaching to the problem itself. (Boud \& Feletti, 1991; Bridges \& Hallinger, 1992; Delisle, 1997; Dods, 1997; Hoffman \& Ritchie, 1997; Hmelo \& Evensen, 2000; Norman, 1988; Norman \& Schmidt, 1992; Stepien, Gallagher, \& Workman, 1993). Barrows (1986) also indicated that PBL is a flexible teaching method, the definition of which may differ in accordance with the teaching design and the skill of teachers. To summarize the viewpoints of the discussed literature, PBL has the following characteristics:

(1) Using an ill-structured problem as the focus of organizing a curriculum and scenario of learning:

The most crucial characteristic of PBL is to focus on an illstructured problem to organize a curriculum and learning scenario and to initiate teaching and learning processes, thereby inspiring students to learn, explore, and develop the necessary professional knowledge and problem-solving tools required in the future (Albanese \& Mitchell, 1993; Barrows, 1996; Fogarty, 1997; Gallagher et al., 1995; Savoie \& Hughes, 1994; Stepien \& Gallagher, 1993). The primary feature of unstructured problems is that each problem may differ according to individual learner backgrounds; thus, the problem is difficult and may not have a single correct solution or formula. During the investigation of unstructured problems, students are able to develop skills of meta-cognition that allows them to monitor, critique, and direct their own inference skills through problem-solving (Barrows, 1985; Stepien \& Pyke, 2000). Therefore, an appropriately designed problem is the most crucial element in PBL (Savoie \& Hughes, 1994).

\section{(2) Learners become stakeholders:}

PBL is a student-centered teaching and learning model. Students can pursue meaning and understanding of matters through self-directed learning (Barrows, 1996; Boud \& Feletti, 1991; Savoie \& Hughes, 1994; Trop \& Sage, 2002). When solving a problem, a special role is given to students. This role contributes to the students' association to the old and new knowledge, understanding of the importance of special problem-solving strategies, and how to re-apply the problemsolving strategies in the future (Gallagher \& Stepien, 1996; Hmelo \& Ferrari, 1997).

\section{(3) Teacher as a trainer in cognition and meta-cognition:}

When teaching with a PBL approach, teachers must assume the role of a curriculum designer, learning or question-solving partner, supporter and director of learning, and evaluator of learning results (Arambula-Greenfield, 1996; Barrows, 1988; Bridges \& Hallinger, 1992; Delisle, 1997; Hmelo \& Ferrari, 1997; Stepien \& Gallagher, 1993; Trop \& Sage, 2002). Teachers manage the process of PBL by adjusting the PBL process, role-playing, and monitoring students' participation. In addition, evaluations are constantly performed throughout the process to determine the learning progress and results of students (Trop \& Sage, 2002).

\section{(4) Encouraging group cooperation and learning:}

According to Barrows (1986), group cooperation and learning is a necessary feature of PBL. Each group member must cooperate with each other as a learner and question-solver. Providing and perceiving different viewpoints that are shared among group members are useful for the clarification of complex matters, thereby improving the efficiency of cooperation (Kelson \& Distlehorst, 2000; Schmidt \& Moust, 2000). Group discussion is also useful for teaching individuals to cope with different viewpoints, and to facilitate high-level cognitive skills such as inference and knowledge-building. Moreover, group discussion also assists students in expressing their own understanding and perspectives when they are unable to convince other group members (Faidley, Evensen, Salisbury-Glennon, Glenn, \& Hmelo, 2000; Kelson \& Distlehorst, 2000).

\section{(5) Multiple evaluation methods:}

PBL is a constructivism-based teaching and learning model. Therefore, the evaluation of PBL is based on constructivism, cognitive psychology, and situational learning, and meets the teaching and evaluation requirements in scientific education (Moreno, 1999; NRC, 1996). Proponents of PBL typically advocate numerous evaluation methods, and perform authentic assessment using attractive, valuable, significant, and real questions that target specific evaluation standards, thereby fully demonstrating the learning process and results (Brooks \& Brooks, 1993; Nagel, 1996; Wiggins, 1993). Furthermore, students' abilities can be shown and provided as a feedback for course efficiency (Glasgo, 1997). Previous studies have tended to categorize the evaluation of PBL as "content," "process," and "outcomes" (Barrows \& Tamblyn, 1980; Glasgo, 1997; Hsu, 1999; Swanson, Case, \& van der Vleuten, 1991). Inference skills, question-solving intelligence, group work, and communication skills can be evaluated by those conducting the three categories of PBL evaluation (Allen et al., 1996; Barrows, 1985; Barrows \& Tamblyn, 1980; Walton \& Matthews, 1989).

\subsection{CONNECTION BETWEEN LUCE CHAPEL IN TUNGHAI UNIVVERSITY AND GEOMETRY IN} MATHEMATICS

Picture 1 is Luce Chapel which is a significant building in Tunghai University and a landmark of Taichung City. The design of Luce Chapel is a mixture of traditional and innovative concepts. Taoism embraces the concept of "materialization from nothingness, and substantiation from nihility." In architecture, this concept is elaborated as being "columnless, beamless, and wallless" in the past and having "column, beam, and wall" in the present. Picture 2 shows the thin exterior structure of Luce Chapel expands on these 
concepts by employing a novel concept of "column is also beam is also wall. Therefore, the appearance and architectural structure of Luce Chapel can serve as a teaching aid creation tool and a good teaching material that can be applied to the PBL system. Moreover, parts of its basic and advanced geometric concepts can be expressed using the teaching aid model.

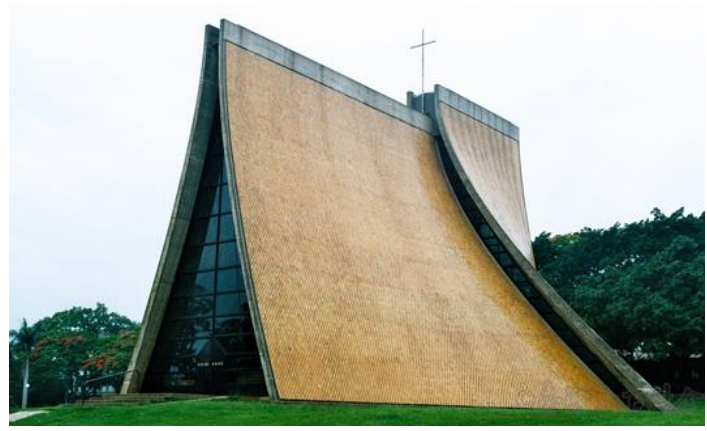

Picture 1 Luce Chapel

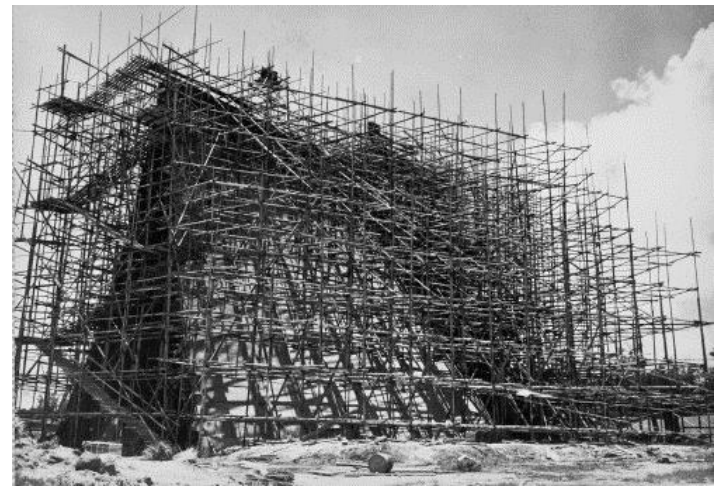

Picture 2 Building structure of Luce Chapel

\section{a. For Elementary School Students}

a-1. The concept of 3-dimensional space :The model of Luce chapel will be designed by piling up the building blocks. Students will be asking to describe by looking at the outward appearance the solid structure of the model. It be a single (or combination of some) prismoid(s), depending on the students' observation. The concept shows as in Picture 3.

a-2. The concept of symmetry: Introduce to students the concept of symmetry. Ask them to justify whether the chapel is symmetric or not. (Can it be proved by counting the building blocks?)

a-3. The concept of elementary plane geometry : We will also make some different layouts of the model. By piecing together these layouts, students can learn how to get a solid figure.

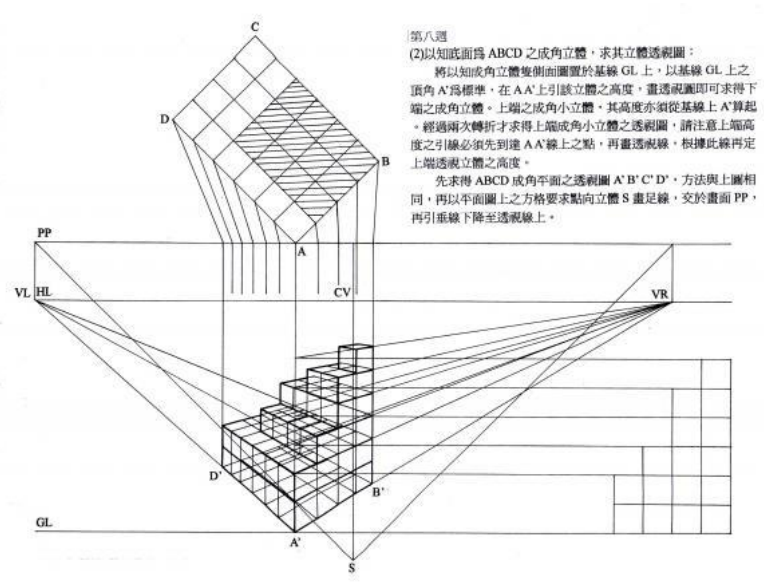

Picture 3 The Architectural Structure in 3-dimensional of Luce Chapel

\section{b. For Junior High School Students}

b-1. Estimation of the surface area : Students can estimate the surface area by counting the area of outwards part of the building blocks. One can also introduce to them the concept of the error.

b-2. Estimation of volume :Building blocks of the model are different kinds of prismoids. Students will be ask to compute the volume of each kind of prismoid and then to estimate the volume of the chapel.

$b-3$. The concept of sequence and series : In computing the number, the area of outward part and the volume of the building blocks of the model, students are ask to develop the computing methods by use of the concepts of an arithmetic progression or a geometric progression.

\section{c. For Senior High School Students}

c-1. Conic sections : The two sides of the chapel are in fact constructed by two hyperboloids. By projecting the hyperboloids to a plane, students are asked to find a suitable equation for the hyperbolic. By observing the model of the chapel, they are also asked to know how to determine an equation of a hyperbolic from giving points.

c-2. The space vectors: The outward normal vector of each building block is unique. Students are asked to find the difference between the normal vectors in the model and those in the hyperboloids of the two sides of Luce chapel. The space vector as shown in Picture 4.

c-3. Something about the Graph Coloring Problem : Students are asked to color the outward appearance of the building block model and the planar layouts. They have to find the smallest number of colors so that the neighboring regions have different colors. 


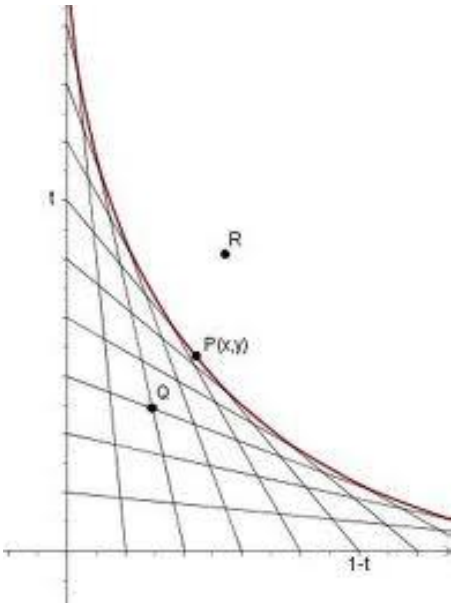

Picture 4 The space vectors of Luce Chapel

\section{d. Advanced geometry: for university students}

d-1. Calculus : Students are asked to analyze the equation of the hyperbolic such as the monotonicity and concavity, and discuss the relationship between these properties and the structure of the chapel.

d-2. Euclidean geometry : Students are asked to compute the dihedral angles of the chapel and those between the building blocks of the model. Moreover, to inlay smoothly the building blocks without gaps, which mathematical theories do we need? Is it related to the Parallel Axiom?

d-3. Elementary differential geometry : Students are asked to realize the geometric properties of the hyperboloids in two sides of the chapel. They include the tangent vectors, the normal vectors and the computation of the space curvature. Furthermore, the minimal distance problem in the chapel can also be considered by finding the minimal geodesics in the hyperboloid.

\subsection{FURTHER RESEARCH}

It is recommended that future studies thoroughly examine the connection between the mathematical theories and the characteristics of Luce Chapel at Thunghai University by using theories such as PBL and brain-storming. In addition, a teaching aid prototype should be developed through demonstration, assembling, envisioning, and analyzing of the teaching aid implementation at the scene to easily and specifically show the mathematical concepts and enable the students to have a deeper understanding of these concepts. The teaching aids should be further improved, completed, and promoted to effectively assist mathematical teaching at various stages.

\section{Acknowledgement}

This project is partially supported by a Taiwan NSC grant (NSC 100-2511-S-029-001-). The author would like to express his thanks to Prof. Fang-Bo Yeh, Prof. Ying-Chyi Chou and Mr. Yan-Shuo Chen for their constructive comments and assistance.

\section{References}

Albanese, M. A., \& Mitchell, S. 1993. Problem-based Learning: A Review of Literature on its Outcomes and Implementation Issues. Academic Medicine. 68(1): 52-81.

Allen, D. E., Duch, B. J., \& Groh, S. E. 1996. The Power of Problem-based Learning in Teaching Introductory Science Courses. New Directions for Teaching and Learning. 68: 43-52.

Arambula-Greenfield, T. 1996. Implementing Problem-based Learning in a College Science Classroom. Journal of College Science Teaching. 26(1): 26-30.

Barrows, H. S., \& Tamblyn, R. M. 1980. Problem-based Learning: An Approach to Medical Education. New York: Springer.

Barrows, H. S. 1985. How to Design a Problem-based Curriculum for the Preclinical Years. New York: Springer Publishing Company.

Barrows, H. S. 1986. A taxonomy of Problem-based Learning Methods. Medical Education. 20: 481-486.

Barrows, H. S. 1988. The Tutorial Process. Revised Edition. Springfield, Illinois: Southern Illinois University School of Medicine.

Barrows, H. S. 1996. Problem-based Learning in Medicine and Beyond: A Brief Overview. New Directions for Teaching and Learning. 68: 3-11.

Boud, D., \& Feletti, G. 1991. Introduction. In D. Boud \& G. Feletti (Eds.). The Challenge of Problem Based Learning. New York: St. Martin's Press. 230

Bridges, E. M. 1992. Problem-based Learning for Administrators. (ERIC Document Reproduction Service No. EA 023 722).

Bridges, E. M. \& Hallinger, P. 1992. Problem-based Learning for Administrators. Eugene, OR: ERIC Clearinghouse on Educational Measurement, University of Oregon.

Brooks, J. G., \& Brooks, M. G. 1993. In search Of Understanding: The Case For Constructivist Classroom. Alexandria, Virginia: Association for Supervision and Curriculum Development.

Delisle, R. (Ed.). 1997. How to Use Problem-based Learning in the Classroom. Alexandria, VA: Association for Supervision and Curriculum Development.

Dods, R. F. 1997. An Action Research Study of the Effectiveness of Problembased Learning in Promoting the Acquisition and Retention of Knowledge. Journal for the Education of the Gifted. 20(4): 423-437.

Faidley, J., Evensen, D. H., Salisbury-Glennon, J., Glenn, 1., \& Hmelo, C. E. 2000. How Are We Doing? Methods of Assessing Group Processing in a Problem Based Learning Context. In D. H. Evensen \& C. E. Hmelo (Eds.), Problem-Based Learning-A Research Perspective on Learning Interactions. New Jersey: Lawrence Erlbaum Associates, Publishers.

Fogarty, R. 1997. Problem-Based Learning and Other Curriculum Models for the Multiple Intelligence Classroom. Illinois, Arlington Heights: IRI/SkyLight Training and Publishing, Inc.

Gallagher, S. A., \& Stepien, W. J. 1996. Content Acquisition in Problem-based Learning: Depth Versus Breadth In American Studies. Journal for the Educational of the Gifted. 19(3): 257-275.

Gallagher, S. A., Sher, B. T., Stepien, W. J., \& Workman, D. 1995. Implementing Problem-based Learning in Science Classrooms. School Science and Mathematics. 95(3): 136-146.

Glasgo, N. A. 1996. New Curriculum for New Times: A Guide to StudentCentered, Problem-based Learning. Thousand Oaks, CA: Corwin Press.

Hmelo, C. E., \& Ferrari, M. 1997. The Problem-based Learning Tutorial: Cultivating Higher Order Thinking Skills. Journal of the Education of the Gifted. 20(4): 401-422.

Hmelo, C. E., \& Lin, X. 2000. Becoming Self-directed Learners: Strategy Development In Problem-Based Learning. In D. H. Evensen, \& C. E. Hmelo (Eds.), Problem-based learning: A Research Perspective on Learning Interactions. Mahwah, NJ: LEA. 227-250.

Hoffman, B., \& Ritchie, D. 1997. Using Multimedia to Overcome the Problems With Problem Based Learning. Instructional Science. 25: 97-115.

Hsu, Y. C. 1999. Evaluation Theory in Problem-based Learning Approach. Paper presented at the National Convention of the Association for Educational Communications and Technology (21st, Houston, TX, February 10-14, 1999) (ERIC Document Reproduction Ser-232 vice No. ED 436 148).

Kelson, A. C. M., \& Distlehorst, L. H. 2000. Groups in Problem-based Learning (PBL): Essential Elements in Theory and Practice. In D. H. Evensen \& C. E. Hmelo (Eds.), Problem-based Learning-A Research Perspective on Learning Interactions. New Jersey: Lawrence Erlbaum Associates, Publishers.

Moreno, N. P. 1999. K-12 Science Education Reforma Primer for Scientists. BioScience. 49(7): 569-576.

Nagel, N. G. 1996. Learning Through Real-world Problem Solving: The Power of Integrative Teaching. Thousand Oaks, California: Corwin Press, Inc. 
National Research Council (NRC). 1996. National Science Education Standards. Washington, D.C.: National Academy Press.

Norman, G. R. 1988. Problem Solving Skills, Solving Problems and Problembased Learning. Medical Education. 22: 279-286.

Norman, G. R. \& Schmidt, H. G. 1992. The Psychological Basis of Problembased Learning: A Review of the Evidence. Academic Medicine. 67(9): $557-565$.

Savoie, J. M. \& Hughes, A. S. 1994. Problem-based Learning as Classroom Solution. Educational Leadership. 52(3): 54-57.

Schmidt, H. G. 1993. Foundations of Problem-based Learning: Some Explanatory Notes. Medical Education. 27(5): 422-432.

Schmidt, H. G., \& Moust, J. H. C. 2000. Factors Affecting Small-group Tutorial Learning: A Review of Research. In D. H. Evensen \& C. E. Hmelo (Eds.), 233 Problem-based learning-A research perspective on learning interactions. New Jersey: Lawrence Erlbaum Associates, Publishers.

Stepien, W. J., Gallagher, S. A., \& Workman, D. 1993. Problem-based Learning for Traditional and Interdisciplinary Classrooms. Journal for the Education of the Gifted. 16(4): 338-357.
Stepien, W. J. \& Pyke, S. L. 1997. Design Problem Based Learning Units. Journal of the Education of the Gifted. 20(4): 380-400.

Stepien, W. J., Senn, P. R., \& Stepien, W. C. 2000. The Internet and ProblemBased Learning-developing Solutions Through The Web. Arizona: Zephyr Press.

Swanson, D. B., Case, S. M., \& van der Vleuten, C. P. M. 1991. Strategies for Student Assessment. In D. Boud \& G. Feletti (Eds.). The Challenge Of Problem Based Learning. New York: St. Martin's Press.

Torp, L., \& Sage, S. 2002. Problems as Possibilities: Problem-based Learning for K-12 Education. Alexandria, VA: Association for Supervision and Curriculum Development.

Walton, H. J. \& Matthews, M. B. 1989. Essentials of Problem-based Learning. Medical Education. 23: 542-558.

Wiggins, G. 1993. Assessment: Authenticity, Context, and Validity. Phi Delta Kappan, 75(3)(Nov., 1993): 200-214. 